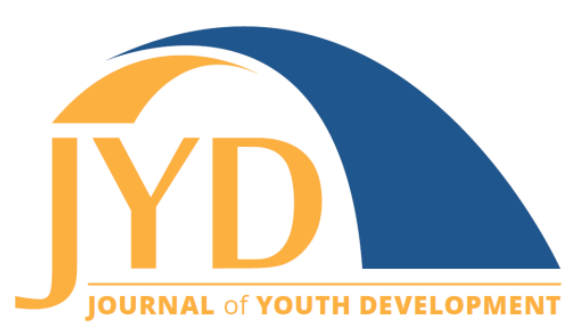

http://jyd.pitt.edu/ | Vol. 15 Issue 6 DOI 10.5195/jyd.2020.954 | ISSN 2325-4017 (online)

\title{
Positive Youth Development Theory in Practice: An Update on the 4-H Thriving Model
}

\author{
Mary Elizabeth Arnold \\ National 4-H Council \\ marnold@fourhcouncil.edu
}

\section{Ryan J. Gagnon}

Clemson University

rjgagno@clemson.edu

\begin{abstract}
The 4-H Thriving Model predicts that participation in high-quality 4-H programs helps youth thrive and that thriving youth achieve key developmental outcomes, thus illuminating the process of positive youth development in 4-H. This paper provides an update on the 4-H Thriving Model, with particular attention to model modifications based on additional research. The paper then describes the formation of the Advancing the 4-H Thriving Model Task Force, a 3-year project chartered by the national 4-H Program Leaders Working Group (PLWG). The paper describes how the work of the task force will support efforts related to the professional development of 4-H youth development professionals and volunteers, replication of and further research on the 4-H Thriving model, and organizational alignment across the national 4-H system.
\end{abstract}

Key words: 4-H Thriving Model, youth development, program theory; program evaluation; professional development

\section{Introduction}

Like many youth organizations using a positive youth development (PYD) approach, 4-H continues to evolve and improve its practice of youth development. In their commentary on the current status of the 4-H program, Borden et al. (2014) identified several key areas for improvement including (a) increasing professional development for 4- $\mathrm{H}$ staff and volunteers, particularly in the area of program quality; (b) developing better program evaluation processes that assess outcomes and the quality of the program that leads to those outcomes; and (c)

(cc) EY New articles in this journal are licensed under a Creative Commons Attribution 4.0 License. This journal is published by the University Library System, University of Pittsburgh and is cosponsored by the University of Pittsburgh Press. The Journal of Youth Development is the official peer-reviewed publication of the National Association of Extension 4-H Youth Development Professionals and the National AfterSchool Association. 


\section{4-H Thriving Model Update}

addressing the lack of a standard 4-H program implementation, something the authors cite as critical to achieving the first two points. The critiques put forth by Borden et al. (2014) were echoed by Roth and Brooks-Gunn (2016) in their comprehensive call for advancing the field of youth development to the next level, which they refer to as "youth development 3.0" (pg. 188). The authors propose that youth development 3.0 should pay increasing attention to developing better definitions and measurement for youth development, making advances in the design and evaluation of programs, focusing on programs as a context for youth development, and integrating both prevention and promotion practices.

In developing the 4-H Thriving Model, Arnold $(2015,2018)$ began to address the concerns raised by Borden et al. (2014) and to advance the field of youth development as proposed by Roth and Brooks Gunn (2016). The 4-H Thriving Model predicts that participation in high-quality youth development programs helps youth thrive, and thriving youth achieve key developmental outcomes. The model illuminates the process of positive youth development in $4-\mathrm{H}$ programs in particular, with theoretical and practical applicability to other programs employing a positive youth development approach (Arnold \& Gagnon, 2019). The 4-H Thriving model is based on the extensive body of research in youth development and builds on the 5Cs model that resulted from the 4-H Study of Positive Youth Development (Lerner \& Lerner, 2013).

As a predictive model of positive youth development, the 4- $\mathrm{H}$ Thriving Model was tested and refined over two preliminary waves of data collection, with results supporting both the model's structure and its measurement. This testing led to a few refinements to the model as originally proposed, a more parsimonious measurement model, and a suite of program evaluation instruments (Arnold \& Gagnon, 2019).

The theoretical paper describing the model (Arnold, 2018) was received with considerable enthusiasm across the 4-H system, the result of which was numerous invitations for presentations on the model and its implications for use in youth development programs. In 2018 and 2019, the lead author presented webinars; keynote addresses; and day-long, inperson trainings to state 4-H programs, regional 4-H program leaders' meetings, and national level 4-H stakeholder groups. As these presentations took place, momentum built for the potential advancement of the model across the national 4-H system. Along with interest came increased demand for professional development materials and opportunities for 4-H staff and volunteers, something that Arnold (2018) predicted as critical to a successful adoption of the model. 
Despite the positive response to the model and its potential positive impact on $4-\mathrm{H}$, three main concerns were raised regarding its common use across the $4-\mathrm{H}$ system. The first addressed the need for additional testing to ensure the model's applicability with diverse 4-H youth participants across a variety of program settings. The second concern was that the model would take 4- $\mathrm{H}$ in a wholly new direction, thus abandoning the frameworks that 4- $\mathrm{H}$ has used in the past. The third concern was that the model needed to be further developed from an equity perspective (Fields, 2020). Enthusiasm and critiques together point clearly to the need to work together across the 4- $\mathrm{H}$ system to continue the model development, address concerns that have been raised, and ensure the model is used consistently across the 4-H system.

The purpose of this paper is threefold. First, this paper provides an update on the 4-H Thriving Model since its original theoretical proposal (Arnold, 2018). The second purpose is to describe the work of the 4-H Program Leaders Working Group (PLWG) task force that was formed in 2019 to advance the 4-H Thriving Model through professional development, further research, and intentional organizational alignment. The final purpose is to consider the implications of the 4-H Thriving Model for youth development practice that is informed by theory and contemporary advances in developmental science.

\section{The 4-H Youth Development System and the Need for a Theoretical Model}

The national 4-H system has a complicated organizational chart, with many entities and stakeholders involved in establishing its priorities and directions. 4- $\mathrm{H}$ is part of the national Extension System, supported in part by the National Institute of Food and Agriculture (NIFA) through funding to the nation's land-grant universities (LGUs). 4-H National Headquarters is part of the Division of Youth and 4-H in the Institute of Youth, Family, and Community at NIFA. 4-H Headquarters focuses on ensuring 4-H program quality, equitable access and opportunity, partnerships, and learning strategies. Federal funding for $4-\mathrm{H}$ is augmented through the support of National 4-H Council, a private partner located in Chevy Chase Maryland, that provides fundraising, brand management, communication, legal, and fiduciary services to the national 4-H system. National 4-H Council also plays an instrumental role in convening the national program areas, events, and priorities of the 4-H system. Funding from each LGU's state legislature, combined with county support, completes the publicly funded portion of the 4-H program. In addition, grants and other forms of support for 4-H programs are frequently secured though state 4-H foundations and local 4-H fundraising efforts. 


\section{4-H Thriving Model Update}

4-H program priorities are determined and guided through a partnership of national stakeholders, including 4-H National Headquarters, National 4- $\mathrm{H}$ Council, the Extension Committee on Policy for 4-H (ECOP 4-H), and the state 4-H program leaders from each LGU working through the PLWG. The National Association of Extension 4-H Youth Development Professionals (NAE4-HYDP) promotes the profession of 4-H youth work, providing professional development, leadership, and recognition opportunities for $4-\mathrm{H}$ professionals.

Locally, 4-H is delivered at the county or parish level by 4-H educators under the leadership of a statewide 4-H program located at a state LGU. Local stakeholder interests and community needs often determine program direction and offerings. This responsiveness to locally determined needs is an important aspect of Extension work in communities (Garst \& McCawley, 2015).

\section{A Theoretical Model of Youth Development}

The first reason the 4-H Thriving Model was developed was to improve 4- $\mathrm{H}$ program planning and evaluation through the use of a standard theoretical model. As noted by Arnold \& Silliman (2017), there is no consistent model or framework of PYD used across the 4-H program. Instead, a variety of frameworks are used, some with little or no science to support them. The 4-H Thriving Model was first introduced as a theory of change model for planning 4-H programs in a paper included in a special journal issue devoted to updating Extension methods and practices (Arnold, 2015). In the original paper, the 4-H Thriving Model is presented as an "umbrella" model that translates research into a program theory of change and under which local 4-H programs can be planned (Arnold, 2015, p. 56). As such, the intention is not for the model to be implemented with absolute fidelity, but rather for it to serve three purposes: first, to provide a clear theory of change for 4-H programs; second, to establish scientific support for the process of youth development; and third, to illuminate the specific ways youth programs work, under which conditions and time, and with which youth (Bornstein, 2019). The model itself was developed based on a synthesis and analysis of current youth development literature in response to several key concerns related to positioning 4- $\mathrm{H}$ as a youth development organization (Arnold, 2018).

The National Study of 4-H Youth Development conducted by Lerner and his colleagues at Tufts University provided the first scientifically supported national level evidence for $4-\mathrm{H}$ as an 


\section{4-H Thriving Model Update}

effective youth development program (Lerner \& Lerner, 2013). The study also produced a model of youth development to guide the work of all youth-serving organizations using a positive youth development approach. The model, informally called the "Five Cs" (Geldhof et al., 2015), built on and scientifically tested the Five Cs framework put forth by Pittman et al. (2003). The Five Cs model predicts that youth who experience positive and supportive relationships with adults and who have opportunities for leadership and skill building will show positive development as indicated by the five Cs of competence, confidence, caring, connection, and character (Lerner \& Lerner, 2013). The five Cs in turn lead to a young person who contributes back to society; contribution is sometimes referred to as the "sixth C." The Five Cs model became the prominent model of youth development across the research literature but remained underutilized in the 4- $\mathrm{H}$ program itself, despite a special handbook volume dedicated to disseminating to practitioners what was learned (Bowers, Geldhof, et al., 2015).

One reason for this underutilization is that the Five Cs model lacked practical specificity on how to translate the research into effective youth development practice, leaving local 4-H educators uncertain about how to use the model in programming (Arnold \& Silliman, 2017; Heck \& Subramanian, 2009). At the same time, however, it is important to note that theoretical models of youth development are always youth-context-time dependent, reflecting the "specificity principle" (Bornstein, 2019, p. 342) and underscoring the need for any theoretical model to be translated into practice with the specific youth, context, and time in mind. Therefore, the adoption of a theoretical model is different than adopting a standard evidenced-based curriculum to be implemented with fidelity across program sites, which is what Borden et al. (2014) were calling for to improve 4-H.

Another reason the Five Cs model was not fully adopted in 4- $\mathrm{H}$ is that the processes through which program characteristics (sustained relationships with mentoring adults) and program activities (promoting life skills and leadership opportunities) led to the five Cs were not articulated, leaving in place the proverbial black box of program understanding (Yohalem \& Wilson-Ahlstrom, 2010). As noted by Roth and Brooks-Gunn (2016), elucidating program processes is critical to understanding how to design and implement effective youth programs. Furthermore, program evaluation increasingly makes sense only if program outcomes are connected to the settings and processes though which they are achieved (Borden et al., 2014; Lerner et al., 2016). 
The final reason the Five Cs model languished in terms of practical use in the 4-H program was the lack of translation into professional development for 4-H staff and volunteers. Publication in research journals alone will not change practice unless research findings are translated into practical training and professional development for program staff and volunteers. Without such training, the Five Cs model remained little more than a way to describe what 4-H does, and because they were difficult to articulate at the practical level, most programs never adopted the model, relying instead on earlier ways of describing how 4-H impacts youth, such the Essential Elements Framework (Kress, 2005) or the Targeting Life Skills Model (Hendricks, 1996).

\section{Aligning 4-H With Positive Youth Development}

A second reason for developing the 4-H Thriving Model was to align the 4-H program more directly with the broader scope of PYD research and practice. Over its evolution as a youth development organization, 4-H has often relied on its own internal descriptors, rather than utilizing research conducted outside of 4- $\mathrm{H}$ to describe program theory and processes. A case in point is the eight critical elements from which the Essential Elements Framework (Kress, 2005) was derived that describe the qualities of a 4-H program necessary for youth development. The list of critical elements was developed through a review of extant literature by the National 4-H Impact Team in 1999 and further distilled into the current four Essential Elements by Cathann Kress (2005), who at the time was the director of National 4-H Headquarters.

With some minor variation, the eight elements identified by the National 4-H Impact Team are reflected in the set of eight youth program quality indicators later identified by Eccles and Gootman (2002). Unlike the 4-H list, which was not used beyond the 4-H program, the list proposed by Eccles and Gootman was established through a rigorous and systematic review of youth programs and is widely recognized and referenced in the youth development field. This left the 4-H program using a different set of youth program standards than most other youth development programs.

In order to increase alignment of the 4-H program with scholarly research in the field of youth development, the 4-H Thriving Model is based on a wide body of youth development theory and research that is easily recognizable to professionals outside $4-\mathrm{H}$. The need to align $4-\mathrm{H}$ programs with youth development research is underscored by the fact that 4- $\mathrm{H}$ is part of the nation's LGU Extension programs that have the distinct commission to provide research-based information to the public, as mandated through the Smith-Lever Act of 1914. The partnership 


\section{4-H Thriving Model Update}

between 4-H and child and adolescent development researchers at LGUs remains underutilized however (Hamilton, 2014), a situation perpetuated by 4-H's continued use of frameworks and models that are not connected to the current research in youth development, research and scholarship that is often taking place at the same LGU as a 4-H program.

\section{Advancing Program Evaluation}

The third reason for developing the 4- $\mathrm{H}$ Thriving Model was to advance program evaluation efforts in 4- $\mathrm{H}$, particularly in the area of youth development outcomes, in addition to program content outcomes, which are more commonly measured. As noted by Borden et al. (2014), Roth and Brooks-Gunn (2016) and Lerner et al. (2016), the evaluation of youth development programs needs to evolve to determine the critical aspects of program quality that lead to impact, and the processes through which youth development happens. Only then can the outcomes of $4-\mathrm{H}$, or any other youth development program, be fully understood.

Advances in 4-H program evaluation have certainly been made in recent years with the advent of 4- $\mathrm{H}$ Common Measures. The result of the 4-H Common Measures project is the identification of a common core of youth outcomes and indicators, a platform for data submission, and training and resources to assist states with local, statewide and regional evaluations. The investment in 4-H Common Measures has assisted the 4- $\mathrm{H}$ system in measuring common program outcomes and has been especially valuable for state 4-H programs without internal evaluation capacity. However, the 4-H Common Measures instruments are focused largely on assessing program content outcomes, albeit with additional short measures of the 4-H experience (based on the presence of the eight 4-H Critical Elements) and the 4-H Universal measure, which is built on a select list of PYD outcomes (e. g. socio-emotional skills and leadership) (National 4-H Council, 2017). Despite the advances made through the 4-H Common Measures efforts, three critical problems remain. First, the 4-H Common Measures are conducted largely as outcome evaluations, independent of measuring program quality or process, and thus provide no way to examine how variations in program quality are related to outcomes, nor to elucidate the processes that led to those outcomes. Second, because of the lack of a program theoretical model, the connection between outcomes and the program contexts and processes that led to their achievement are not known, let alone measured. Understanding program contexts and processes is key to addressing the specificity of the interaction of youth, context, and time (Bornstein, 2019). Finally, common measures data are 
collected independently by states and are not aggregated nationally to tell a large impact story of $4-\mathrm{H}^{1}$

The 4-H Thriving Model complements and advances the work of 4-H Common Measures by providing a theoretical structural model that predicts program effect and connects program outcomes to the program quality and processes that produced it. The 4-H Thriving Model sets the stage for collecting program evaluation data across the country, leading to a greater statement of the impact of $4-\mathrm{H}$ on its participants.

\section{Originally Proposed 4-H Thriving Model $^{2}$}

The 4-H Thriving Model originally proposed by Arnold (2018) has three structures that describe and predict the effect of $4-\mathrm{H}$ programs on youth development (Figure 1).

The first structure is the 4-H developmental context, which is comprised of the setting and experiences provided by $4-\mathrm{H}$ for youth. The developmental context is made up of four elements: (a) facilitating youth sparks, (b) fostering developmental relationships, (c) following principles for high-quality youth development programs, and (d) promoting youth engagement. Youth sparks are defined as a "passion for a self-identified interest or skill, or a capacity that metaphorically lights a fire in an adolescent's life, providing energy, joy, purpose, and direction" (Scales et al., 2011, p. 264). The relationships between youth and adults in 4-H form the second element of the developmental context. Youth-adult relationships are considered developmental when they express care, challenge growth, provide support and empowerment, share power, and expand possibilities for youth (Roehlkepartain et al., 2017). Developmental relationships also grow and change over time in alignment with a young person's developmental needs (Bowers, Johnson, et al., 2015; Li \& Julian, 2012). The third element of a developmental

\footnotetext{
${ }^{1}$ One notable exception was the national call for data in 2018 that invited states to submit data for aggregation using the 4-H Universal Outcomes instrument. The intent of the data collection was to assess outcomes experienced by $4-\mathrm{H}$ youth and to examine variation in outcomes related to variables such as delivery mode, age, gender and level of involvement. In addition, large grant projects funded through National 4-H Council regularly collect robust sets of evaluation data using 4-H Common Measures that could be aggregated and similarly analyzed.

2 The presentation of the 4-H Thriving Model in this paper is brief, focusing on the model's development and testing since the theoretical paper was published. For a full understanding of how the 4-H Thriving Model was developed based on youth development literature, the reader is encouraged to read the theoretical paper (Arnold, 2018) and the paper reporting the first empirical test of the model (Arnold \& Gagnon, 2019).
} 
context is adherence to the eight features of youth development settings identified by Eccles and Gootman (2002): physical and psychological safety, appropriate structure, supportive relationships, opportunities to belong, positive social norms, support for efficacy and mattering, opportunities for skill building, and integration of family, schools and community. The final element is promoting youth engagement in the program, considering the duration, intensity and breadth of participation (Weiss et al., 2005).

\section{Figure 1. Originally Proposed 4-H Thriving Model}

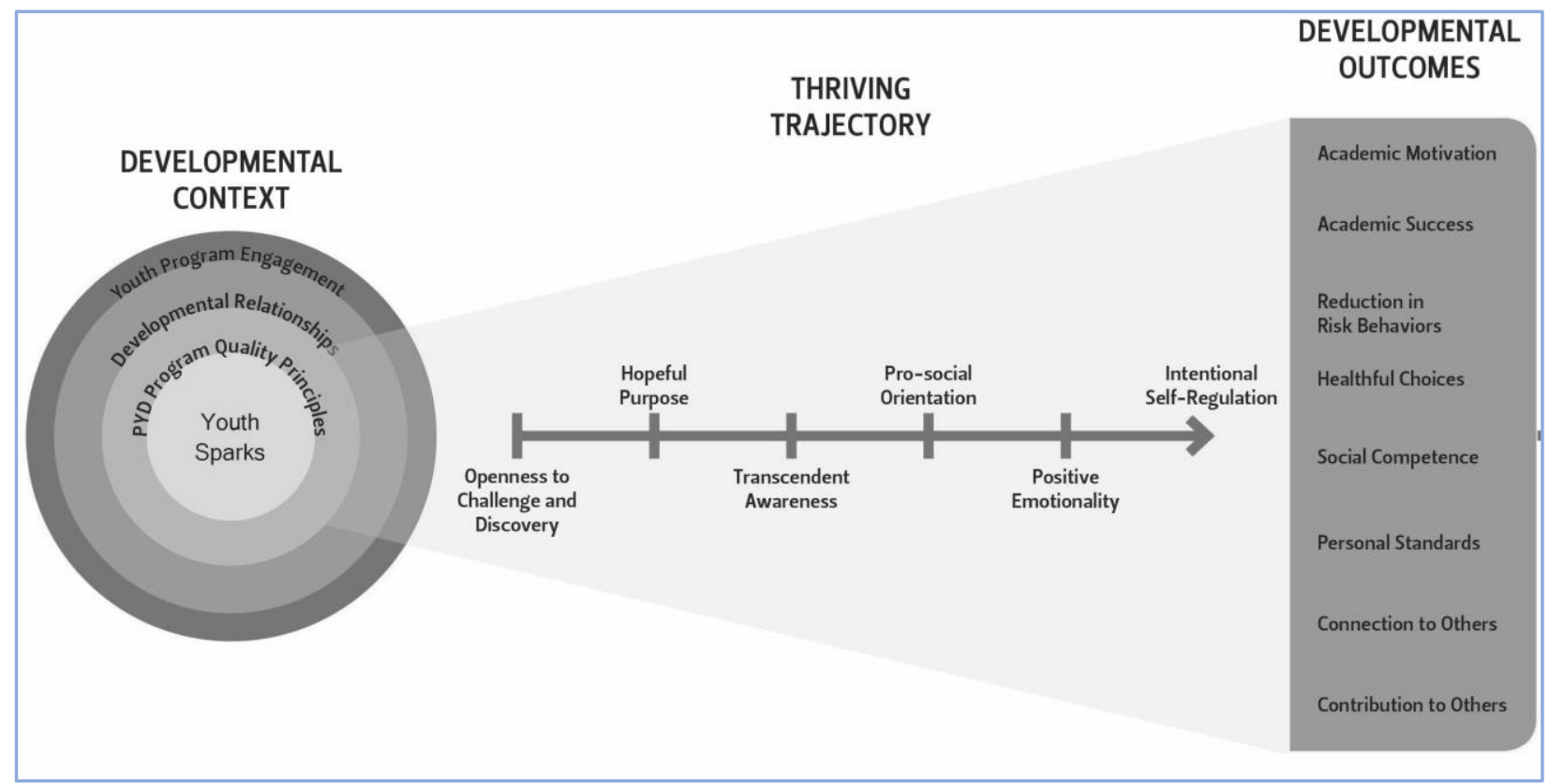

High-quality developmental contexts lead to youth thriving, which is the second structure of the model. The six indicators of youth thriving proposed by Search Institute (2014) are (a) openness to challenge and discovery; (b) a hopeful purpose; (c) an awareness beyond the self (transcendent awareness); (d) a prosocial orientation; (e) positive emotionality; and (f) intentional self-regulation. This part of the model describes the process of PYD, which happens as youth increase their levels of thriving across the thriving indicators.

Thriving youth, in turn, achieve positive youth development outcomes, which constitutes the third structure of the model. Arnold (2018) described how some of these positive youth development outcomes align with the Five Cs (e.g., social competence, personal standards, connection to others, and contribution to others). Additional outcomes were added to the 


\section{4-H Thriving Model Update}

proposed model based on their saliency to the 4-H program (i.e., academic motivation and success, reduction in risk behaviors, and healthful choices).

The proposed 4-H Thriving Model was originally tested in 2017 for measurement and structure with 243 youth participating in 4-H club programs in Oregon (Arnold \& Gagnon, 2019). Statistical testing using structural equation modeling (Kline, 2011) supported a full mediational model, meaning that youth who participated in 4-H programs that provided a high-quality developmental context thrive, and thriving youth achieved positive developmental outcomes (Arnold \& Gagnon, 2019). Whereas the 4-H Thriving model was developed for 4-H specifically, the model has universal application to youth development practice in general. The model articulates the way in which program context and processes lead to positive outcomes, thus elucidating the process of youth development (Roth \& Brooks-Gunn, 2016) and establishing a way to evaluate that process (Lerner et al., 2016).

Based on the 2017 study, the model and its measurement were refined and retested in 2018 with 279 youth in Oregon 4-H clubs using a more parsimonious instrument resulting from the original study (Arnold \& Gagnon, 2020). Confirmatory factor analysis (CFA) confirmed the constructs and measurement in the revised model. Structural equation modeling (SEM) supported the full mediational model of the first study. In the second study $73.8 \%$ of the respondents were female Youth ranged in age from 13 to 19 with a mean age of 15.21 . Seventy-five percent of respondents were White, $15 \%$ were Hispanic, Latino or Spanish origin, and less than $3 \%$ reported other races. It is important to note that the participant demographics reflect the Oregon 4-H program enrollment and are not fully representative of the national 4-H program enrollment, thus emphasizing the critical need for additional research on the model with different youth in different program contexts.

A few important modifications from the theoretical model emerged after two waves of testing, resulting in a revised model, presented in Figure 2 below (Arnold \& Gagnon, 2020):

- Youth engagement did not factor into the developmental context structure in the first study. As a result, in the second study youth engagement was tested as a moderator influencing the relationship between the developmental context and youth thriving. The moderating effect was established in the second study, leading to the understanding that youth engagement is essential if programs are to have an effect on youth thriving (see Figure 2). Identifying youth engagement as a moderator underscores the importance of youth engagement in programs. Even the highest quality $4-\mathrm{H}$ program will 
not have a positive effect if youth do not engage with what is offered. Youth engagement "drives the thriving."

- The thriving indicator of openness to challenge and discovery factored into two separate constructs in the first study. We identified these constructs as openness to challenge and discovery, which describes a willingness to be challenged and to risk trying new things, and growth mindset, which describes a willingness to work hard to accomplish something. Because possessing a growth mindset has become a central tenet of youth development (Haimovitz \& Dweck, 2017), the list of thriving indicators was expanded from six to seven in the revised model (see Figure 2).

- The developmental outcomes of healthful choices and reduction in risk behavior did not factor significantly into the model during the first testing. As a result, these outcomes were dropped from the revised model.

- An additional developmental outcome labeled "personal responsibility," which reflects a young person's dependability and ability to follow through on commitments, was added to the revised model because of the saliency of this outcome to the 4-H program. Personal responsibility factored into the list of developmental outcomes in the second study (Arnold \& Gagnon, 2020).

\section{Figure 2. Revised 4-H Thriving Model}

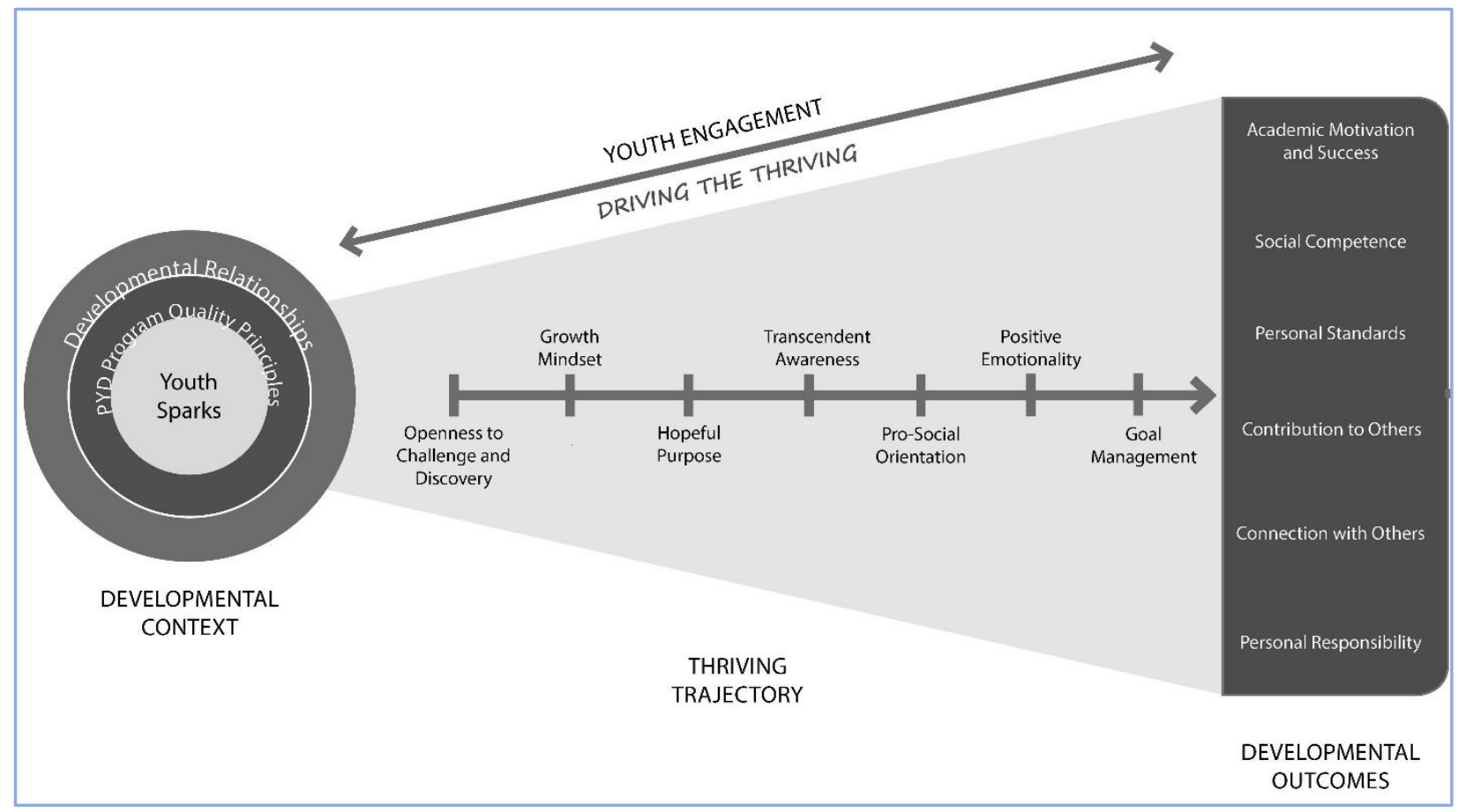


4-H Thriving Model Update

\section{Advancing the 4-H Thriving Model}

The results of the initial testing of the 4-H Thriving Model were received with enthusiasm across the 4-H system, creating buy-in and generating an eagerness to move forward in advancing the model for 4-H. In conversations with 4-H leadership, it became clear that the mechanism to advance the 4-H Thriving Model and to address the valid lingering concerns about its use across the system, was to receive approval for the formation of a PLWG chartered task force. As aforementioned, the PLWG is a representative group of state 4-H program leaders from each region of the country tasked with identifying and supporting key initiatives to advance 4-H youth development work. The PLWG charters these initiatives through an application and review process.

The 3-year PLWG task force, chartered in 2019, entitled "Advancing the 4-H Thriving Model" is composed of three subgroups focused on (a) professional development for 4-H staff and volunteers; (b) further research on the model across diverse youth and settings; and (c) organizational alignment to position the model as a continuation of the work $4-\mathrm{H}$ is already doing, rather than something wholly new, and to ensure systematic, consistent adoption and use of the model across the 4-H system.

\section{Professional Development}

In their 2014 article calling the 4-H program to action, Borden et al. highlight the need for the professional development of 4-H professionals and volunteers and program evaluation that is focused on both outcomes and program quality. Arnold (2018) stated that the primary reason for proposing the model was the need to illuminate the processes through which 4-H promotes positive youth development. The call to elucidate these processes followed the completion of the National 4-H Study of Youth Development (Lerner \& Lerner, 2013), which determined what needs to happen for 4-H to promote PYD, but not how to do it (Arnold \& Silliman, 2017; Heck \& Subramanian, 2009). The pressure to understand how PYD is promoted through program settings and activities has been increasing across the general body of youth development literature as well (Lerner et al., 2016; Roth \& Brooks-Gunn, 2016).

Program processes are the program's theory of action (Funnell \& Rogers, 2011). A theory of action describes what program settings and activities are required for the program to have its anticipated effect. The 4-H Thriving Model was developed as an "umbrella model" under which local 4-H educators could develop their own local programs that promote PYD through youth 


\section{4-H Thriving Model Update}

thriving (Arnold, 2015, p. 53). Because most 4-H programs are decentralized from a national directive and designed and implemented at the state or local level, it is the local 4-H educator who has the most control over developing programs that promote thriving (Arnold \& Cater 2016). Therefore, providing professional development to train 4-H educators on the principles of creating a high-quality developmental context, and to design and implement program activities that promote youth thriving, is perhaps the most critical link in ensuring the full use of the 4-H Thriving model, and promoting PYD consistently across the 4-H system (Arnold, 2015).

The professional development of 4-H educators has been a focus of 4- $\mathrm{H}$ for over 40 years. In the 1980 s the 4-H system began identifying the professional competencies required of 4- $\mathrm{H}$ youth workers, resulting in the 4-H Professional Research and Knowledge Base (Hutchins, 1990). By 2004, this set of competencies had evolved into the Professional Research and Knowledge Competencies ([PRKC]; Stone \& Rennekamp, 2004), which were updated in 2017, and currently referred to as the 4-H PRKC 2017 (NIFA, 2017). Of the six categories of competencies in the PRKC 2017, three are pertinent to the 4-H Thriving Model. First, the necessary professional competencies in the area of youth development include youth growth and development, youth development theory, and youth development practice. A second area focuses on competencies related to youth program development, including needs assessment, program design, delivery, and evaluation. A third area relates to volunteer development, which adds another layer of professional development need-preparing volunteers to plan and implement 4-H programs in alignment with the 4-H Thriving Model.

Despite the identification of these core competencies, the PRKC has been minimally used to direct systematic capacity building efforts for $4-\mathrm{H}$ professionals. Some state $4-\mathrm{H}$ programs use the competencies to describe 4-H youth work to new professionals and as a guide for assessing professional development needs (Heck et al., 2009) and for designing professional development opportunities (Garst et al., 2007). However, there has been no national, system-wide adoption of or facilitation of the use of the PRKC to guide professional development efforts in 4-H.

Professional competency in the areas of youth development, youth program development, and volunteerism are key aspects of reaching the full benefit of using the 4- $\mathrm{H}$ Thriving Model for several reasons. First, understanding development across childhood and adolescence is necessary to help youth thrive. Take for example the thriving indicator of emotional regulation, which develops over childhood and adolescence. We are typically not surprised if a very young child has an emotional meltdown over not receiving something they desire (like a cookie). But 
we would take notice if a senior in high school had a similar tantrum over not getting something they desired. The difference is in the developmental maturity of emotional and self-regulation that takes place between early childhood and late adolescence. In order for 4-H programs to be high quality, the developmental nuances of creating developmental settings and promoting youth thriving must be clearly understood (Jones \& Deutsch, 2012). Second, designing and implementing high-quality 4-H programs requires professional competency. Without training in the areas of program design, delivery, fidelity, equity, and evaluation, 4-H educators have no understanding of the many important ingredients necessary for program success. Effective program design, delivery, and evaluation in 4- $\mathrm{H}$ is largely conducted at the local level by local educators. Thus, the strength and quality of 4-H programs that promote youth thriving, and in turn, achieve youth development outcomes, lie in the competency of local 4-H educators (Arnold \& Cater, 2016). Finally, because the 4-H program is delivered in a large scale by $4-\mathrm{H}$ volunteers, it is critical that the local 4-H educator not only possess personal competencies, he or she must also have an intentional strategy and resources to train the volunteers to implement 4-H programs in fidelity with the 4-H Thriving Model.

Led by four $4-\mathrm{H}$ professionals with expertise in professional and volunteer development, curriculum, and youth development, the first sub-group of the PLWG task force is focusing on the professional development of 4-H educators and volunteers. The group will work together to identify critical training and educational needs, training resource development, and professional development strategies to support the advancement of the 4- $\mathrm{H}$ Thriving Model across the 4- $\mathrm{H}$ system.

\section{Further Research: What Works for Whom Under What Conditions?}

The 4-H Thriving Model represents the first attempt to articulate the 4-H program's theory of change to elucidate the processes through which 4-H achieves its outcomes (Chen, 2004). Understanding processes that lead to outcomes provides a critical foundation for professional development-if we don't know how 4-H works its magic, how can we prepare 4-H professionals to conduct effective programs? A program theory of change is different than a logic model. Logic models describe what happens in a program, whereas program theory is both descriptive and predictive (Patton, 2002). Program theory provides an explanatory account of how a program works, with whom, and under what conditions (Astbury \& Leeuw, 2010), and identifies the causal processes through which program success takes place (Pawson, 2013). As noted by Arnold (2015), without a clear articulation of a program's underlying theory, and an understanding of the causal processes that promote youth development, the implementation of 


\section{4-H Thriving Model Update}

4-H programs is left to chance, and the measurement of the resultant outcomes is suspect at best. A well-defined program theory of change illuminates the necessary ingredients for program success.

The research conducted to date on the 4-H Thriving Model has confirmed the theory of change for the 4-H program. This theory predicts that: (a) $4-\mathrm{H}$ programs that provide high-quality developmental contexts for youth with a focus on activities that help youth thrive lead to (b) thriving youth, and (c) thriving youth achieve key developmental outcomes. In this theory, youth thriving is a mediating causal process (Chen, 2004), meaning that the process of youth thriving is what connects the developmental context of $4-\mathrm{H}$ and the outcomes for youth participating in 4-H programs. Research on the model has also established a moderating effect, namely youth engagement, that influences the program's effect on youth thriving - that is, the more a young person is engaged in $4-\mathrm{H}$, the greater likelihood of increased thriving (Arnold \& Gagnon, 2020).

One of the key criticisms of adopting the 4-H Thriving Model is the limited research that has been conducted to date, a criticism that is both fair and also an expected part of the process of theory development. What has been established so far is a main effect structural model that supports the theory of change for the 4-H program. This step goes a long way toward addressing some of the concerns about 4-H as a youth development organization raised by Borden and colleagues (2014) and about youth development programs in general (Roth \& Brooks-Gunn, 2016). However, continued refinement of the model is necessary to understand what works for whom under what conditions, a phrase often associated with realistic program evaluation approaches (Pawson \& Tilley, 1997), and consistent with the Bornstein's (2019) specificity principle that underscores the interaction of youth, context, and time. Both realistic evaluation and the specificity principle are premised on the idea that the processes that lead to a positive program effect vary from context to context and discovering and illuminating these differences strengthen a program's overall theory. Additional research on the 4-H Thriving Model will provide insight into program modifications or adaptions that may be necessary for 4- $\mathrm{H}$ to be effective with diverse youth across diverse settings. For example, much continues to be uncovered about the interaction of culture, race, identity, gender, personal experience, history, and socio-economic statuses with the effect of programs on youth.

Additional research will now focus on three aims: (a) a replication of the original studies across the 4-H system, (b) continuing confirmation and refinement of the model's theory and its 


\section{4-H Thriving Model Update}

measurement with diverse youth and settings, and (c) identifying the specific processes through which youth are positively impacted by 4-H participation. For example, when working with youth from diverse backgrounds there are experiences, values, and expectations, often invisible or implicit, that come into play between the program's intention and the youth's needs and experiences.

Recent consensus research highlights that youth have varying learning and developmental needs, influenced in large part by their contexts, brain malleability, and presence of buffering relationships (Bonnie \& Backes, 2019; Cantor et al., 2019). The result of this research is a new emphasis on the science of learning and development, which is leading advances in contemporary developmental science and will surely have a key influence on youth development practice in the years to come (Lerner, Geldhof, \& Bowers, 2019). Consistent with program design principles identified in the science of learning and development, the need to elucidate the processes of youth development is key to ensuring that 4- $\mathrm{H}$ and all PYD programs generate intended outcomes for youth. A young person who has suffered trauma and its impact on brain development, for example, may require different forms of support and interaction from a program's context to ensure a positive impact on that young person's development. The driving research question moving forward is: How does participation in the 4-H program enhance thriving, for which youth, in which contexts, and, in particular right now, as the COVID-19 pandemic and calls for social justice mark this point in history, for youth at this point in time (Arnold, 2020; Arnold \& Rennekamp, 2020).

The second subgroup of the Advancing the 4- $\mathrm{H}$ Thriving Model Task Force, led by three 4-H specialist-level program evaluators and a lead methodologist, will focus first on a system-wide main-effect replication of the 4-H Thriving Model study. From there the group will work to identify the next steps for continued research to further test and refine the underlying theory of the 4-H Thriving Model to ensure its applicability for all 4-H participants and program settings. Results of ongoing research will inform the work of the professional development group as we learn more about what works for which youth under which conditions, and how best to foster thriving in 4-H youth, with theoretical application to all youth development programs.

\section{Enhancing Organizational Alignment Across the 4-H System}

In their work on building evaluation capacity, Preskill and Boyle (2008) outlined the multidimensional commitment required for organizations to change evaluation practice. This framework is useful for understanding the multiple dimensions that must work together across 


\section{4-H Thriving Model Update}

the 4-H system if the 4-H Thriving Model is to reach its full potential. Adopting the 4-H Thriving Model will require a synergistic commitment to enhancing the practice of $4-\mathrm{H}$ youth development work (e.g., through professional development, training resources, additional research and program evaluation), and the organization of the $4-\mathrm{H}$ system to support what is practiced. Preskill and Boyle highlight that clear leadership committed to the change, creating a culture that supports the change, developing systems and structures to facilitate the change, and ongoing honest conversation about the change process are key elements of connecting practice and the organization. The result is a continuous transfer of learning and alignment between developing effective youth development practice and the greater 4-H organization.

Establishing agreement among stakeholders to the priorities for the 4- $\mathrm{H}$ system is a daunting undertaking, but one that must be accomplished to ensure coherency of the 4- $\mathrm{H}$ experience for all youth. There are some promising exemplars, however. For example, the aforementioned 4-H Common Measures, a project sponsored by National 4- $\mathrm{H}$ Council, has established outcomes and measures for the three priority program areas established by 4- $\mathrm{H}$ National Headquarters: Science, Healthy Living, and Civic Engagement. 4-H Common Measures has also allowed for standard evaluation data across large-scale grant programs with National 4-H Council, such as the 4-H CS Pathway sponsored by Google, and the Youth Voice: Youth Choice Program sponsored by the Walmart Foundation. Other alignments are now evident with the establishment of the PLWG chartered working groups, and the appointment of a liaison from the PLWG to the NAE4-HYDP Board. The PLWG chartered groups ensure that collaborative work generated in the 4- $\mathrm{H}$ system is approved and supported at a higher level in the organization and connected to the professional development opportunities through NAE4-HYDP.

The third subgroup of the PLWG task force will work to support the alignment of the 4-H organizational system around the advancement of the 4- $\mathrm{H}$ Thriving Model. This group led by two state-level 4-H specialists will focus on several key aspects to promote organizational alignment. These include (a) providing communication related to the 4- $\mathrm{H}$ Thriving Model with key stakeholder groups across the 4-H system, (b) providing clarity on how the model builds on what is already practiced in 4- $\mathrm{H}$, (c) facilitating the connection of the 4- $\mathrm{H}$ Thriving Model to 4-H Common Measures, (d) promoting NAE4-HYDP professional development priorities that are in alignment with the model, and (e) encouraging investment in capacity building and organizational learning. 


\section{Conclusion and Implications}

As a result of the positive interest in advancing the 4- $\mathrm{H}$ Thriving Model across the national 4- $\mathrm{H}$ system, we are poised to build on what has been developed thus far, and unite the 4-H program, perhaps for the first time, around a common program theory model. The call for membership applications for the PLWG Advancing the 4-H Thriving Model task force in the summer of 2019 resulted in 55 complete applications, from all five Extension regions. Since late 2019, the task force leadership and its subgroups have been meeting regularly and preparing plans to guide their work over the next 3 years.

Moving forward from this juncture will take considerable investment in terms of dollars, time, and energy. Doing so, however, will help us ensure the best 4- $\mathrm{H}$ programming for the youth we serve, and realize some key portions of the national 4-H strategic plan (NIFA, 2019). To not move forward in a united way at this point risks a gradual devolution of the 4-H Thriving Model into 50 or more different forms, with each state continuing to do $4-\mathrm{H}$ in its own way. If this happens we will miss the chance to determine the large-scale impact of $4-\mathrm{H}$, let alone ensure that all youth who participate in $4-\mathrm{H}$ receive the same high-quality experience that we know leads to youth thriving and key developmental outcomes. In short, if we do not harness the interest and expertise of the system's 4-H professionals to transform research into practice, 4- $\mathrm{H}$ will not rise to meet the challenges for improvement put forth by Borden et al. (2014), nor will it lead the field of youth development 3.0 (Roth and Brooks-Gunn, 2016) as it should, given its placement in the country's LGUs.

While the immediate goal of this paper was to share an update on the development of the 4-H Thriving Model, and the efforts in place to facilitate its advancement across the 4-H system, the paper has broader implications for youth development beyond $4-\mathrm{H}$. The first implication is the way in which the 4-H Thriving model advances our theoretical understanding of the process of PYD, as called for by Roth and Brooks-Gunn (2016). The 4-H Thriving model has illuminated one process, youth thriving, that connects youth outcomes to high-quality developmental settings. The constructs included in the model are not specific to $4-\mathrm{H}$, but rather universal constructs of program settings and youth development drawn from multi-disciplinary research in youth, child, and adolescent development. The 4-H Thriving model, as a theoretical model of youth development, can be used as a theoretical base for other youth-serving organizations beyond $4-\mathrm{H}$. 
The key to using the model in other youth development settings lies in the recognition that the model is not something to be implemented with fidelity, but rather used theoretically, describing one way that programs can promote positive youth development. As such, whereas the applicability of the theory of the model (high-quality contexts lead to youth thriving, and thriving youth achieve developmental outcomes) may be more or less universal among youth development programs, the specifics of how the model is translated into practice will be different from program to program. Recent advances in developmental science have underscored the nature and importance of idiopathic development and its implications for research (Nesselroade, 2019) and youth development practice (Lerner et al., 2019). Advancing understanding of the specificity of youth in context, and its implications for research and practice is the cornerstone of current developmental science (Cantor et al., 2019). Rather than seeking a standard implementation model that fits every youth program, and thus violating Bornstein's (2019) specificity principle, all youth development practitioners must translate theoretical constructs into actions that fit the specific needs of each youth participant each time and each place a program takes place, with particular attention given to the racial, ethnic, and cultural diversity of the youth the program serves.

\section{References}

Arnold, M. E. (2015). Connecting the dots: Improving Extension program planning with program umbrella models. Journal of Human Sciences and Extension, 3(2) 48-67.

Arnold, M. E. (2018). From context to outcomes: A thriving model for 4-H youth development programs. Journal of Human Sciences and Extension, 6(1), 141-160.

Arnold, M. E. (2020). America's moment: Investing in positive youth development to transform youth and society. Journal of Youth Development, 15(5), 16-36. https://doi.org/10.5195/jyd.2020.996

Arnold, M. E., \& Cater, M. (2016). Program theory and quality matter: Changing the course of Extension program evaluation. Journal of Extension [On-line], 54(1). http://www.joe.org/joe/2016february/a1.php

Arnold, M. E., \& Gagnon, R. J. (2019). Illuminating the process of youth development: The mediating effect of thriving on youth development program outcomes. Journal of Human Sciences and Extension, $7(3), 24-51$.

Arnold, M. E., \& Gagnon, R. J. (2020). Going deeper: Exploring and confirming factors that promote thriving in 4-H youth development programs [Manuscript submitted for publication].

Arnold, M. E., \& Rennekamp, R. A. (2020). A time like no other: 4-H youth development and COVID-19. Journal of Extension, 58(3). https://joe.org/joe/2020june/comm1.php 
4-H Thriving Model Update

Arnold, M. E., \& Silliman, B, (2017). From theory to practice: A critical review of positive youth development frameworks. Journal of Youth Development, 12(2), 1-20.

\section{https://doi.org/10.5195/JYD.2017.17}

Astbury, B., \& Leeuw, F. L. (2010). Unpacking black boxes: Mechanisms and theory building in evaluation. American Journal of Evaluation, 31(3), 363-381.

https://doi.org/10.1177/1098214010371972

Bonnie, R. J., \& Backes, E. P. (Eds.). (2019). The promise of adolescence: Realizing Opportunity for all Youth. National Academies Press.

Borden, L. M., Perkins, D. F., \& Hawkey, K. (2014). 4-H Youth Development; The past, the present, and the future. Journal of Extension, 52(4). https://www.joe.org/joe/2014august/comm1.php

Bornstein, M. H. (2019). Fostering optimal development and averting detrimental development: Prescriptions, proscriptions and specificity. Journal of Applied Developmental Science, 23(4), 340345.

Bowers, E. P., Geldhof, G. J., Johnson, S. K., Hilliard, L.J., Hersberg, R. M., Lerner, J. V., \& Lerner, R., M. (2015). Promoting positive youth development: Lessons from the 4-H study. Springer. https://doi:10.1007/978-3-319-17166-1 6

Bowers, E. P., Johnson, S. K., Warren, D. J. A., Tirrell, J. M., \& Lerner, J. V. (2015). Youth-adult relationships and positive youth development. In E. P. Bowers, G. J. Geldhof, S. K. Johnson, L. J. Hilliard, R. M. Hershberg, J. V. Lerner, \& R. M. Lerner (Eds.), Promoting positive youth development: Lessons from the 4-H study (pp. 97-120). Springer. https://doi:10.1007/978-3319-17166-1 6

Cantor, P., Osher, D., Berg, J., Steyer, \& Rose, T. (2019). Malleability, plasticity and individuality: How children learn and develop in context. Journal of Applied Developmental Science, 23(4), 307-337. https://doi.org/10.1080/10888691.2017.1398649

Chen, H. T. (2004). Practical program evaluation: Assessing and improving planning, implementation, and effectiveness. Sage.

Eccles, J., \& Gootman, J. (Eds.). (2002). Community programs to promote youth development. National Academy Press.

Fields, N. I. (2020). Literature Review: Exploring 4-H Thriving Through an Equity Lens. National 4-H Council-ECOP 4-H.

Funnell, S. C., \& Rogers, P. J. (2011). Purposeful program theory: Effective use of theories of change and logic models. Jossey Bass.

Garst, B. A., Hunnings, J. R., Jamison, K., \& Hairston, J. (2007). Development of a comprehensive new 4-H Extension agents training program using a multi-module approach and the 4-H Professional 
4-H Thriving Model Update

Research, Knowledge, and Competencies (4-HPRKC) taxonomy. Journal of Extension, 45(1). https://www.joe.org/joe/2007february/a3.php

Garst, B., \& McCawley, P. (2015). Solving problems, ensuring relevance, and facilitating change: The evolution of needs assessment within Cooperative Extension. Journal of Human Science and Extension, 3(2), 26-47.

Geldhof, G. J., Bowers, E. P., Mueller, M. K., Napolitano, C. M., Callina, K. S., Walsh, K. J., Lerner, J. V., \& Lerner, R. M. (2015). The five C's model of positive youth development. In E. P. Bowers, G. J. Geldhof, S. K. Johnson, L. J. Hilliard, R. M. Hershberg, J. V. Lerner, \& R. M. Lerner (Eds.) Promoting positive youth development: Lessons from the 4-H study (pp. 161-186). Springer. https://doi.org/10.1007/978-3-319-17166-1 9

Haimovtiz, K., \& Dweck, C. S. (2017). The origins of children's growth and fixed mindsets: New research and a new proposal. Child Development, 88(6), 1849-1859. https://doi:10.1111/cdev.12955

Hamilton, S. F. (2014). On the 4-H Study of Positive Youth Development. Journal of Youth and Adolescence, 43(6), 1008-1011. https://doi: 10.1007/s10964-014-0121-z

Heck, K. E., \& Subramanian, A. (2009). Youth development frameworks (University of California 4-H Center for Youth Development Monograph). University of California.

Heck, K. E., \& Subramanian, A., \& Carlos, R. (2009). Use of the PRKC tool in assessment of staff development needs: Experiences from California. Journal of Extension, 473). https://www.joe.org/joe/2009june/a7.php

Hendricks, P.A. (1996). Targeting Life Skills Model. Iowa State University Extension.

Hutchins, G. K. (1990). Agent specialization and the 4-H PRK Model. Journal of Extension, 28(4), https://www.joe.org/faes-joe/joe/1990winter/a3.php

Jones, J. N., \& Deutsch, N. L. (2012). Social and identity development in an after-school program: Changing experiences and shifting adolescent needs. Journal of Early Adolescence, 33(1), 17-43. https://doi.org/10.1177/0272431612462628

Kline, R. B. (2011). Principles and practice of structural equation modeling ( $3^{\text {rd }}$ ed.). The Guilford Press.

Kress, C. (2005). Essential Elements of positive youth development. In Strengthening positive youth development environments (pp. 20-23). University of Wisconsin Extension 4-H Program. https://doi.org/10.1177/0272431612462628

Lerner, R. M., Geldhof, G. J., \& Bowers, E. (2019). The science of learning and development: Entering a new frontier of human development theory, research, and application. Journal of Applied Developmental Science, 23(4), 305-306. https://doi.org/10.1080/10888691.2019.1630995

Lerner, R. M., \& Lerner, J. V. (2013). The positive development of youth: Comprehensive findings from the 4-H study of positive youth development. National 4-H Council. 
Lerner, R. M., Lerner, J. V., Urban, J. B., \& Zaff, J. (2016) Evaluating programs aimed at promoting positive youth development: A relational development systems-view. Applied Developmental Science, 20(3), 175-187. https://doi.org/10.1080/10888691.2015.1082430

Li, J., \& Julian, M. M. (2012). Developmental relationships as an active ingredient: A unifying working hypothesis of "what works" across intervention settings. American Journal of Orthopsychiatry, 82(20), 157-166). https://doi:10.1111/j.1939-0025.2012.01151.x

National 4-H Council (2017). 4-H Common Measures 2.0 reference table. Author.

National Institute for Food and Agriculture. (2017). Growing together: 4-H Professional, Research, Knowledge, and Competencies. Author.

National Institute for Food and Agriculture. (2019). 4-H Youth Development Strategic Plan: a 2025 Vision. Author.

Patton, M. Q. (2002). Qualitative research and evaluation methods ( $3^{\text {rd }}$ ed.). Sage.

Nesselroade, J. R. (2019). Developments in developmental theory and research. Journal of Applied Developmental Science, 23(4), 346-348.

Pawson, R. (2013). The science of evaluation: A realist manifesto. Sage.

Pawson, R., \& Tilley, N. (1997). Realistic evaluation. Sage.

Pittman, K., Irby, M., Tolman, J., Yohalem, N., \& Ferber, T. (2003). Preventing problems, promoting development, encouraging engagement: Competing priorities or inseparable goals? Forum for youth investment.

Preskill, H., \& Boyle, S. (2008). A multidisciplinary model of evaluation capacity building. American Journal of Evaluation, 29(4), 443-459. https://doi:10.1177/1098214008324182

Roehlkepartain, E. C., Pekel, K., Syvertsen, A. K., Sethi, J., Sullivan, T., K., \& Scales, P. C. (2017). Relationships first: Creating connections that help young people thrive. Search Institute.

Roth, J. L., \& Brooks-Gunn, J. (2016). Evaluating youth development programs: Progress and promise. Applied Developmental Science, 20(3), 188-202. https://doi:10.1080/10888691.2015.1113879

Scales, P. C., Benson, P. L., \& Roehlkepartain, E. C. (2011). Adolescent thriving: The role of sparks, relationships, and empowerment. Journal of Youth and Adolescence, 40, 263-277. https://doi.org/10.1007/s10964-010-9578-6

Search Institute (2014). The Search Institute model of thriving orientation: Overview of its evolution through recent funding from the Thrive Foundation for Youth. [Unpublished paper]. Author.

Stone, B., \& Rennekamp, R. (2004). New foundations for the 4-H Youth development profession; 4-H professional research, knowledge, and competencies study. Conducted in cooperation with the National 4-H Professional Development Task Force. National 4-H Headquarters, CSREES, USDA. https://4-hhistorypreservation.com/eMedia/eOneTimeReports/New Foundations.pdf 
Journal of Youth Development | http://jyd.pitt.edu/ | Vol. 15 Issue 6 DOI 10.5195/jyd.2020.954

4-H Thriving Model Update

Weiss, H. B., Little, P. M. D., \& Bouffard, S. M. (2005). More than just being there: Balancing the participation equation. New Directions for Youth Development, 105, 15-31.

https://doi:10.1002/yd.105

Yohalem, N., \& Wilson-Ahlstrom, A. (2010). Inside the black box: Assessing and improving quality in youth programs. American Journal of Community Psychology, 45(3-4), 350-357. https://doi:10.1007/s10464-010-9311-3g 